\title{
Correction to: The Right to Know and the Right Not to Know Revisited
}

\section{Roger Brownsword ${ }^{1,2} \cdot$ Jeff Wale ${ }^{2}$}

Published online: 7 March 2019

(C) National University of Singapore and Springer Nature Singapore Pte Ltd. 2019

\section{Correction to: Asian Bioethics Review (2017) 9:3-18 \\ https://doi.org/10.1007/s41649-017-0012-1}

In the original publication the title reads "The Right to Know and the Right Not to Know Revisited: Part One". The paper consisted of both Part One and Part Two hence the title has to be corrected.

Publisher's Note Springer Nature remains neutral with regard to jurisdictional claims in published maps and institutional affiliations.

The online version of the original article can be found at https://doi.org/10.1007/s41649-017-0012-1

Roger Brownsword

roger.brownsword@kcl.ac.uk

Jeff Wale

jwale@bournemouth.ac.uk

1 King's College London, London, UK

2 Bournemouth University, Poole, UK 